\title{
Study on the Improvement of Health Information Literacy for Students in Medical Colleges
}

\author{
Shu Li, Na Liu* \\ Institute of Medicine and Nursing, Hubei University and Medicine \\ *Communication Author
}

Keywords: medical colleges; health information literacy; improvement; training mode optimization

Abstract: This paper investigates the current situation of health information literacy of medical college students, and with the analysis of survey results, basic characteristics of health information literacy of medical college students are obtained, and in the light of these features, the optimization measures of health information literacy training course, teaching mode and teaching methods are effectively put forward.

\section{Introduction}

With the continuous improvement of living conditions in China, people pay more and more attention to health quality. China's Ministry of health has launched a nationwide health literacy monitoring survey. As a medical college, college students are going to grow up as the backbone of health, and having good health information literacy is one of the basic requirements.

Health information literacy (HIL) is the penetration of information literacy and health literacy two concepts and integration, refers to the awareness of health information needs, quality and applicability of retrieval, acquisition and evaluation of health information, analysis, understanding and use of health information to make correct decisions in a series of health ability. Based on the survey and analysis of health information literacy of medical college students represented by Hubei Medical College, this paper puts forward a teaching optimization method to enhance health information literacy according to the survey results.

\section{Content and Results of the Survey}

\subsection{Investigation Preparation}

The design of the preliminary investigation questionnaire, reference to the part of the national health and Family Planning Commission "national health literacy monitoring questionnaire" in question, the questionnaire is designed to understand the Chinese residents' health knowledge and skills, and these simple topics should be essential knowledge of medical college students so based on this, questionnaire, and increase the information literacy.

From the 5 dimensions, the questionnaire surveys the health information literacy of students, including the awareness level of health information, the acquisition of health information, the 
evaluation ability of health information, the level of health information application, and the ethics of health information. The level of awareness of health information, investigating the students access to health information consciousness and cognitive level, encounter related problems can be related to the degree of health information; the ability to access health information, the ability of students to access health information through a variety of ways, whether to search useful information from a certain extent; health information evaluation ability investigation of students in the network environment is now out of order information, have certain screening and analysis ability, a good evaluation of the accuracy and correctness of the information; application of water health information, students can access to health information will be applied in practice to solve the health problems related to health information ethics; the process of investigation and analysis, the students in the acquisition, application of health information, whether to follow relevant ethical norms and regulations Consciousness.

\subsection{Investigation Process}

The survey using self-administered questionnaire, sampling by stratified sampling from each grade, gender, professional school of medicine in Hubei, according to the proportion of selected students participated in the questionnaire. In order to ensure smooth and accurate fill in the questionnaire, most of the choice model, refine the topic involves 5 dimensions, including students seeking health information initiative, access to information channels, information skills and information screening methods etc. At the same time, as a supplementary investigation, we targeted for students and the school has been part of the research in the Affiliated Hospital of employment of graduates from face-to-face interviews, understand the medical talents of high level understanding of health information literacy and job requirements for health information literacy.

\subsection{Survey Results}

A total of 1020 questionnaires were sent out, 963 effective answers were obtained, the effective recovery rate was $94.4 \%$, and 10 graduates and 10 graduate students successfully completed the interview survey. According to the statistics and analysis of the results of Excel and SPSS 22, the basic characteristics of health information literacy of undergraduate medical colleges and universities are as follows.

1) The level of health information consciousness is generally good

As a medical college student, due to the correlation between professional and health, health information awareness is higher than ordinary residents. Students are generally interested in health information. $76.3 \%$ of the students had to solve everyday problems with health information awareness and habits, $53.6 \%$ of the students are willing to pay attention to health information related news, literature and science and technology achievements, $47.8 \%$ of the students think that the school should be more open and some related courses or lectures on health information.

2) The ability to obtain health information needs to be improved

The questionnaire results show that the way the students access to health information in addition to classroom teachers, the main network, including search engine, Internet news, library database resources, WeChat or micro-blog push etc., there is less information is the way television, newspaper etc.; $95.2 \%$ of the students that use search engines to get health information, $90.5 \%$ of the students said they used the school library database resource access to health information needs (literature retrieval experiment course requirements), but said to be able to master various database retrieval methods of senior students accounted for only $17 \%$. It shows that the current students' health information acquisition methods are relatively single (the highest frequency of search engines), and the ability to use database to accurately retrieve related information needs to be 
strengthened and improved.

3) The evaluation ability of health information is still insufficient

The popularization of network technology developed and mobile terminal, way and sources make students obtain health information is abundant, but the quality of information is uneven, with advantages and disadvantages. Students' ability to discriminate information is still insufficient. 53.7\% of students have had no experience in sharing health information, and $72.1 \%$ of students have difficulty in judging the authenticity and reliability of information.

4) Limited application of health information

At present, there are two main aspects of students' application of health information: solving daily health and health problems (76.3\%) and solving class problems (58.6\%). According to the research of the school and students have been in-depth interviews in the Affiliated Hospital of employment of graduates, undergraduate application level of health information is not enough, the application is too narrow, the method is mostly derived from the literature retrieval course in learning CBM, PUBMED senior database retrieval function, the depth is not enough, after work not very quick to apply theoretical knowledge to the actual situation.

5) The moral standard of health information follows good

According to the survey results, the students in the process of acquisition, application of health information in the most well follow the basic moral standard, including not free to disseminate health information or forwarding rumors (91.7\%), willing to pay a fee to obtain valuable health information resources (60.2\%), indicating that students of network security and ethics the general awareness of good, and the benign migration to health information ethics consciousness.

\section{Optimization of Health Information Literacy Training Process}

After understanding the characteristics of Medical College Students' health information literacy, we believe that we can optimize teaching mode and curriculum system from several aspects, in order to improve students' health information literacy and meet the needs of practical applications.

\subsection{Advanced Training in Undergraduate Education}

As a medical college student, the education of health information literacy should go through all the time, and the current school's health information literacy education is mainly reflected in the 2 courses of Library Education and document retrieval. In view of this situation, suggestions in the curriculum system, should adopt advanced training mode, from one to five have set up health information literacy courses for the formation of the corresponding system, each class is about 12 , and the difficulty increases gradually, with each new undergraduate professional knowledge acquisition and the demand for health information literacy class curriculum integration specialty pharmaceutical disciplines, really runs through each learning stage.

\subsection{Use PBL Teaching Method and Pay Attention to Formative Evaluation}

Problem-based learning (PBL) is adopted in classroom teaching. The problem of increasing difficulty is set up in different learning stages of each grade, so that students can work together to drive learning and solve practical problems. In the course of teaching, teachers are not only exporting knowledge, but are involved in the process of solving problems, and give some guidance

and encouragement in time. From the 5 dimensions of health information literacy, the students' ability to acquire information and evaluate information is consciously cultivated. The teaching process focus on formative evaluation, and the traditional mode in the final exam at different, suggestions for the development of student self-assessment, peer assessment and teacher evaluation 
in the learning process, improve students' initiative of autonomous learning, stimulate students' interest in learning, the teaching focus on every aspect of every class, students have to participate in sense, to learn efficiently.

\subsection{Application and Practice}

To change the current status of "heavy theory and light practice" in the course of health information literacy courses, a new pattern of "heavy application and practice" is constructed. A substantial increase in experiment class hours, give students hands-on practice time; suggestions practice to enhance health information literacy links, such as in the application process to assign the students the medical literature retrieval task, strengthen the ability of students to obtain information and screening; encourage students to participate in the tutor's research projects, especially actively participate in research collect information, etc., can be applied to real knowledge frontier practice disciplines, improve the application level of health information, but also to improve the level of scientific research, manufacturing, deep and lay a solid foundation for future employment.

\section{Acknowledgments}

Supported by 2015 Annual Project of Hubei Educational Science Planning(2015GB180).

\section{References}

[1] Medical Library Association. Health Information Literacy: definitions [EB/OL]. Available from: https://www.mlanet.org/resources/healthlit/define.html [Accessed 16th March 2014].

[2] Han Yunfeng, Lou Fengge, Ge Jie, Jia Yuehui, Xie Zhiping. Investigation of health information literacy of college students in a Medical College of preventive medicine research and training strategy of [J]. forum, 2016,8:565-567573.

[3] Lu Jianyu, Zhou Juzhi, Ai Yubing, Zhou Guoxiang. Investigation and analysis of health information literacy cognition and needs of students in a vocational medical college in Ningbo. [J]., China's rural health management, 2015,3:363-366. 